\title{
mEiEa
}

\section{Archival Research Methods and Music Industry Pedagogy}

\author{
Andrew Mall \\ Northeastern University \\ This paper was presented at the 2018 International Summit of the \\ Music \& Entertainment Industry Educators Association \\ March 22-24, 2018
}

https://doi.org/10.25101/18.24

\section{Abstract}

In this article, I discuss the value of archival research and primary document sources to pedagogy in music industry education. I describe the archival methods I have employed in a research project documenting contemporaneous discourse about the corporate consolidation of Christian record labels within (secular) major record labels in the early 1990s. What challenges face music industry scholars conducting archival research? What is the importance of historical documents to music industry educators today? I suggest that historical case studies, including those substantiated by archival research and primary documents, can be used to model and teach strategic decision making to music industry students.

Keywords: research methods, archival research, music industry history, $C C M$ magazine, Christian music, corporate consolidation
This project was funded by a MEIEA research grant.

\section{Introduction}

In this article, I discuss the value of archival research and primary document sources to pedagogy in music industry education. I describe the archival methods I have employed in a research project documenting contemporaneous discourse about the corporate consolidation of Christian record labels within (secular) major record labels in the early 1990s. Ending a prolonged period of rumors and anticipation, the three largest Christian record labels were all acquired by new corporate parents within a twelve-month period in 1992-93. Reporting on these transactions and their significance practically leap off the pages of the Christian market newsletter The CCM Update, such as the above-thefold headline "Nelson Buys Word; EMI Buys Sparrow" on October 5, 1992. In CCM magazine, Update's parent publication, founding editor and publisher John Styll had been responding to tensions over the intersection of business and faith almost since the magazine's inception (see, e.g., the interviews reprinted in Styll 1991). I have been interested in Styll's editorial approach in CCM and Update for many years, largely because these publication were the largest, most easily accessible source for news about the market and industry for contemporary Christian music. ${ }^{1}$

For historical researchers and music industry scholars, accessing these particular primary sources can be problematic: they are not sufficiently indexed, nor are they easily accessible online or available in many public library or university collections. Thus, in order to learn how the Christian market reported on and reacted to these acquisitions and other forms of corporate consolidation, I had to travel to an archive. Documenting these transactions and transitions has been my primary goal of the archival project, but in conducting this research, I have reflected upon the broad value of archival research to music industry pedagogy. What is the importance of historical documents to music industry educators today? I suggest that historical case studies, in- 
cluding those substantiated by archival research and primary documents, can be used to model and teach strategic decision making to music industry students.

\section{The Archival Project}

As a scholarly field, music industry studies favors timely and up-to-date data over historical research. For example, of the thirteen issues of the International Journal of Music Business Research published between 2012 and early 2018, roughly $20 \%$ of the 39 articles addressed historical topics or case studies (of at least ten years old). ${ }^{2}$ The MEIEA Journal is noticeably more welcoming to historical topics: of the 49 articles published during the same period (2012-17), $38 \%$ discuss historical examples. That said, hardly any of these articles make use of primary documents found in archives, suggesting that archival research is employed only infrequently, if at all, in music industry studies. In part, such prejudice is related to our pedagogical goals: music industry educators use (and teach students to understand and interpret) statistics related to chart data, consumer surveys, fan engagement via social networking, financial information, and streaming in order to teach strategic decision-making in industries that, because they are changing very quickly, operate dramatically differently than they did only ten years ago (see, e.g., Essling, Koenen, and Peukert 2017; Wlömert and Papies 2016; DiCola 2013). Researchers with appropriate levels of access rely on proprietary industry data via BDS, Billboard, the IFPI, Pollstar, the RIAA, SoundScan, and other services and organizations (see, e.g., Fer and Baarsma 2016). Qualitative methods such as interviewing, oral history, and participant/observation help contextualize these quantitative data (see, e.g., Gamble, Brennan, and McAdam 2017; Allington, Dueck, and Jordanous 2015; Marshall 2015).

Music industry scholarship tends to employ all of these research methods and data sources to learn more about the present (or the very-recent past). Data and information collected via archival research, on the other hand, is by definition rooted in the past. Scholarly histories of music industries have largely become the domain of related academic fields such as ethnomusicology, historical musicology, and popular music studies. What is the value of music industry history for music industry training and pedagogy? I argue that we ignore the history of the music and entertainment industries at our own peril: when educators and scholars do not pay enough attention to the messy work of teasing out and comprehending lessons from the historical record, our students are more likely to make similar mistakes or poor strategic decisions. It can be difficult to incorporate history courses into academic curricula that seem to be forever under revision given the fast-paced changes in the industries. Even if we cannot teach an entire course devoted to music industry history, however, music industry instructors can find ways to incorporate historical case studies related to our topics into the courses we already teach, be they applied or scholarly, no matter the subject.

Music industry educators who have the training and resources to conduct primary research ourselves, or who have the opportunity to work with graduate students conducting original research for theses and dissertations, face relatively common challenges of research design. In particular, we need to know where to look for data and what to ask of it once we find it. These challenges, of course, are not inseparable: even the best-framed historical research objectives are subject to change without detailed knowledge of the archives and archival materials in which one expects to find answers. Sometimes the archive itself may precede the research objectives: many interesting projects have emerged because a researcher stumbled across something cool that prompted new questions she had not yet considered. I teach my students that one's research objectives and research methods should always be in dialogue: it is important to have a general sense of one's goals in order to direct and focus your resources during the research process, but it is just as important to be open to failures and surprises, which often lead to new research directions. Research is an iterative process; often we learn new things in the course of our research that require us to return to our earlier assumptions and reframe our objectives. In other words, you should anticipate that your research project changes during the course of conducting research.

My research into the reporting on and reactions to corporate consolidation in the Christian record industry within the pages of $C C M$ magazine and its sister publications is part of a larger project on the boundaries of markets for commercial popular music in the United States. Boundaries are important because they reflect and perpetuate the conditions of inclusion and exclusion. Through boundaries, participants - musicians, professionals, and consumers-learn what is valued and what is forbidden in any given market. Participants involved in the work of cultural intermediation rely on boundaries, both implicitly and explicitly, to legitimize decisions that have real-world consequences for the music and artists to which listeners and audiences have access. ${ }^{3}$ Boundaries are not solid but instead porous and mutable. They change over time, and it is in these moments of change that the discursive work of markets is the most interesting. At the heart of contestations over boundaries are contestations over meaning, and in the Christian market specifically the conflict between commerce and ministry as competing objectives illustrates the central question at the heart of all conflicts within this particular niche market: what is Christian music for? From this perspective, my research into Christian music is broadly valuable to music in- 
dustry studies because it examines the roles of various forces in defining and redefining the boundaries for one niche market over several decades.

Most of my research on the Christian market has been through secondary historical literature and original ethnographic fieldwork, but the Center for Popular Music at Middle Tennessee State University presents a unique opportunity for archival research with primary documents: as far as I have been able to learn, theirs is the only complete collection of CCM magazine (and its related publications) at a public institution. I expected to observe and analyze reactions to the mergers and acquisitions of Christian record labels in the pages of $C C M$, which was the primary source of information about and for the Christian market for three decades (1978-2008). CCM was widely read by professionals and consumers, published relatively objective news items alongside more subjective editorializing, and enabled an engaging exchange of opinions in its letters section (well before these conversations largely moved to online chat rooms, discussion forums, and comments sections). Through my previous research I had already constructed general timelines of the acquisitions and mergers that resulted in today's three major Christian labels (Capitol Christian Music Group; Provident, a subsidiary of Sony Music; and Word, a subsidiary of Warner Music). I had planned to spend a week at the archive targeting those dates in $C C M$, looking for articles, editorials, and reader feedback about intersections between the Christian and general markets, both to substantiate the timelines I had constructed and to evaluate such discourse as a barometer of anxieties over these specific intersections and corporate consolidation in general. I predicted that these primary data would inform my current and future research projects as well as provide a resource when teaching research methods to music industry students.

I found learning the details of intersections between the Christian and general markets through the pages of tactile historical documents to be enormously satisfying. The pure scope and scale of the data that remains to be mined, comprehended, and analyzed, however, is disheartening. For example, late in my first day at the archive, after six hours of paging through early 1980s issues of CCM magazine, I discovered that John Styll had split the magazine into two separate publications in May, 1983 (see Table 1). From that point on, the industry- and trade-related content was published in MusicLine, which was later renamed The MusicLine Update (in 1986) and then The CCM Update (in 1988) and was published until 2002. ${ }^{4} C C M$ magazine itself was redesigned to feature primarily consumer-oriented content. Gone were the professional topics; the magazine began to resemble general market celebrity magazines more closely, especially during the period in 1983-86 when the magazine's official name was changed from Contemporary Christian Music to Contemporary Christian Magazine.

\begin{tabular}{|l|l|}
\hline \multicolumn{2}{|c|}{ CCM Magazine Timeline } \\
\hline 1978 & CCM magazine founded \\
\hline 1981 & CCM resized from tabloid to standard format \\
\hline 1983 & $\begin{array}{l}\text { MusicLine launched; CCM renamed } \\
\text { Contemporary Christian Magazine }\end{array}$ \\
\hline 1986 & $\begin{array}{l}\text { MusicLine relaunched as The MusicLine } \\
\text { Update; CCM renamed (back to) } \\
\text { Contemporary Christian Music }\end{array}$ \\
\hline 1988 & $\begin{array}{l}\text { The MusicLine Update renamed The CCM } \\
\text { Update }\end{array}$ \\
\hline 1999 & Salem Publishing acquires CCM \\
\hline 2002 & $\begin{array}{l}\text { Salem closes The CCM Update; former } \\
\text { content appears in Radio and Records }\end{array}$ \\
\hline 2008 & Salem closes CCM \\
\hline 2009 & Salem re-launches CCM online-only \\
\hline
\end{tabular}

Table 1. CCM magazine timeline.

The effects of this split on my research process and objectives were numerous. First, and most obviously, I had to track discourse and reporting in two publications, not one. (MusicLine and The CCM Update were shorter than $C C M$ magazine but, starting in October 1986, were published biweekly instead of CCM's monthly schedule.) Second, although $C C M$ still published some industry news, it did so infrequently and often indirectly, through oblique references in other articles. Third, although my central objective had been to examine fan discourse about corporate consolidation, that discourse was notably absent following the split. Label acquisitions were reported in MusicLine and The CCM Update far more often than in CCM magazine. The newsletters did not usually feature letters, so there is no way of knowing what readers might have thought about such acquisitions, which accelerated in the 1990s and 2000s. Fourth, MusicLine and The CCM Update published a lot of news, including rumors, which is interesting to read but difficult to digest efficiently and quickly.

\section{Conclusions and Future Directions}

I should not have been surprised that one of the biggest things I learned in the course of this archival research is that a comprehensive study of these discourses in the pages of $C C M$ magazine and its other publications would require more time and resources than I have. As a result-and as I teach my students to anticipate-I have had to reorient my research objectives around other questions to accommodate this discovery. It is useful to imagine one's ideal research and data in the best of all possible worlds, with access to unlimited resources. But researchers live in the real world, with limited contacts, expertise, funds, and time. As a re- 
sult, our research projects are often shaped (and reshaped) as much by the data to which we have access as they are by our original objectives. My project has changed from addressing fan discourse about corporate consolidation to considering the role that John Styll and his writers played in shaping the public conversation over these transactions (and the tensions they engendered within the Christian market) in the pages of CCM magazine, MusicLine, and Update.

Where do we go from here, in terms of the broader applicability of historical research to music industry pedagogy? One suggestion is to frame archival research questions in ways that do not require comprehensiveness, and are able to be addressed with representative samples taken from the historical record and not necessarily the entirety of the historical record itself. For music industry educators and our students, in what ways what might archival research be valuable to music industry pedagogy? Undoubtedly, archival research like that which I am conducting is a source of historical information and is valuable to the extent that we can and do incorporate historical narratives into our courses. The historical examples I have uncovered in my archival research illustrate the broader trajectories and effects of record label consolidation, particularly consolidation that integrates niche into larger markets. Archival research, from this perspective, can provide concrete examples from the past about strategic decision-making in the future. For example, historical narratives (supported by primary documents) could provide a foundation for case studies and other pedagogical resources to support teaching and learning in the classroom.

Music industry scholars have a lot to learn from archival research. We also have a lot to learn from the research process itself: because it can be difficult to predict what one might learn, researchers must be comfortable with ambiguity and able to incorporate new (and often unexpected) data into their decision-making processes. To achieve successful results, researchers must also be able to synthesize data and knowledge from a variety of disparate sources. In other words, archival research is valuable both for the content it uncovers and for the strategies its methods model and teach. Research methods have the potential to teach music industry students skills that will benefit them throughout their careers.

\section{Acknowledgements}

This research was funded in part by a MEIEA faculty research grant; I am grateful to John Simson, Courtney Blankenship, and other members of the 2017 award committee. I conducted the archival research discussed in this article at the Center for Popular Music, Middle Tennessee State University. I am grateful to Greg Reish, director, and his staff for their support and interest in this project.

\section{Endnotes}

1. CCM magazine shares both its name and its acronym with the genre it discusses, contemporary Christian music.

2. The $I J M B R$ is open access, online at https://musicbusinessresearch.wordpress.com/international-journal-of-music-business-research-ijmbr/.

3. On "cultural intermediaries," see Bourdieu (1984, 365-66). Devon Powers (2015) argues for privileging the work of cultural intermediation over the cultural intermediary agents.

4. After The CCM Update ceased publication in 2002, its charts - arguably the newsletter's most popular feature - migrated to Radio \& Records. $R \& R$ launched the Christian charts in its April 19, 2002 issue (no. 1449), accompanied by a featured subsection, "The Explosion of Christian Music" (pp. 33-48) and a regular one-page column branded as "The CCM Update." Successive issues of $R \& R$ confined "The CCM Update," news about the Christian market and Christian charts, to four pages. 


\section{References}

Allington, Daniel, Byron Dueck, and Anna Jordanous.

"Networks of Value in Electronic Music: SoundCloud, London, and the Importance of Place." Cultural Trends 24, no. 3 (2015): 211-22. https://doi.org/10.1080/0954 8963.2015.1066073.

Bourdieu, Pierre. Distinction: A Social Critique of the Judgement of Taste. Translated by Richard Nice. Cambridge, Mass.: Harvard University Press, 1984.

DiCola, Peter. "Money from Music: Survey Evidence on Musicians' Revenue and Lessons about Copyright Incentives." Arizona Law Review 55, no. 2 (2013): 301-70.

Essling, Christian, Johannes Koenen, and Christian Peukert. "Competition for Attention in the Digital Age: The Case of Single Releases in the Recorded Music Industry." Information Economics and Policy 40 (2017): 26-40. https://doi.org/10.1016/j.infoecopol.2017.05.002.

Fer, Adam, and Barbara Baarsma. "Rockonomics Revisited: The Rise of Music Streaming Services and the Effect on the Concert Industry." International Journal of Music Business Research 5, no. 1 (2016): 7-35.

Gamble, Jordan Robert, Michael Brennan, and Rodney McAdam. "A Rewarding Experience? Exploring How Crowdfunding Is Affecting Music Industry Business Models." Journal of Business Research 70 (2017): 25-36.

Marshall, Lee. “'Let's Keep Music Special. F-Spotify': On-Demand Streaming and the Controversy over Artist Royalties." Creative Industries Journal 8, no. 2 (2015): 177-89. https://doi.org/10.1080/17510694.201 $\underline{5.1096618 .}$.

Powers, Devon. "Intermediaries and Intermediation." In The SAGE Handbook of Popular Music, edited by Andy Bennett and Steve Waksman, 120-34. Thousand Oaks, California: SAGE Publications, 2015.

Styll, John, ed. The Heart of the Matter: The CCM Interviews. Nashville: Star Song Communications, 1991.

Wlömert, Nils, and Dominik Papies. "On-Demand Streaming Services and Music Industry Revenues - Insights from Spotify's Market Entry." International Journal of Research in Marketing, The Entertainment Industry, 33, no. 2 (2016): 314-27. https://doi.org/10.1016/j. ijresmar.2015.11.002.
Andrew Mall (Ph.D. University of Chicago, 2012) is Assistant Professor of Music at Northeastern University. His research and teaching focus on research methods; nostalgia, collecting, and consumption; categories of mainstream and underground musics; histories of the recording industries; music festivals; the political economies of evangelical congregational musics; and the organizational practices and hierarchies of small and large institutions in music industries. His current book project is titled Marginalia: Niche Markets, Christian Rock, and Popular Music. He is co-editor, with Jeffers Engelhardt and Monique Ingalls, of the forthcoming volume Studying Congregational Music: Key Issues, Methods, and Theoretical Perspectives.

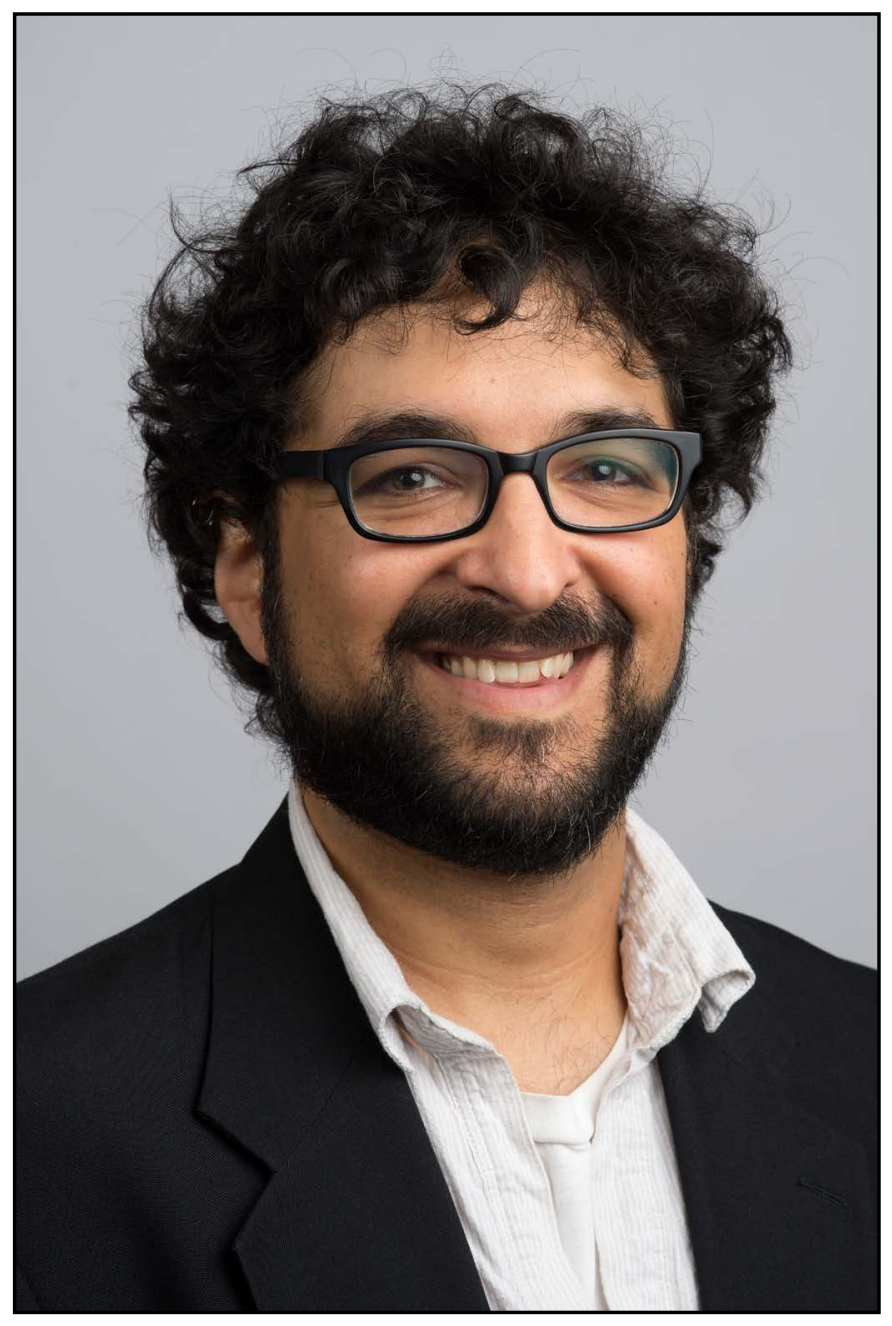




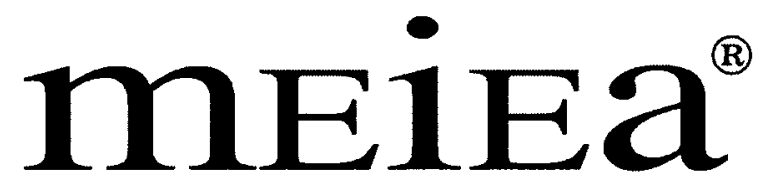

MUSIC \& ENTERTAINMENT INDUSTRY

EDUCATORS ASSOCIATION

\section{PROCEEDINGS OF THE \\ 2018 INTERNATIONAL SUMMIT}

OF THE

\section{MUSIC \& ENTERTAINMENT INDUSTRY EDUCATORS \\ ASSOCIATION}
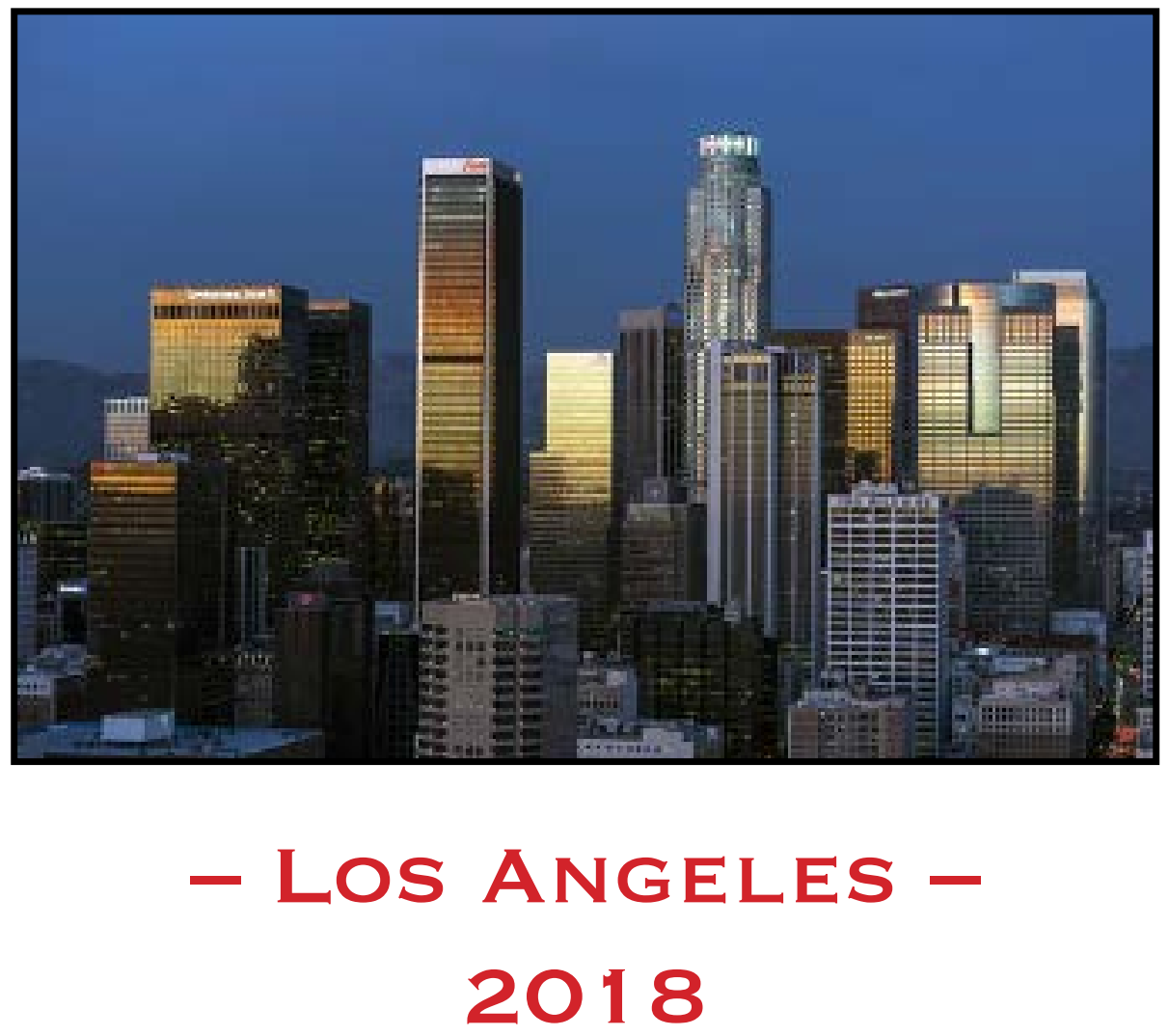

March 22 - 24, $2018 \cdot$ Embassy Suites by Hilton - Los Angeles/Glendale 